\title{
Supply Chain Management Strategies in Terms of Decoupling Points and Decoupling Zones
}

\author{
Joakim Wikner \\ Jönköping University \\ joakim.wikner@decouplingpoints.org
}

\begin{abstract}
Supply chain management is concerned with decisions related to the physical perspective of the enterprise and how the flow of goods and services is arranged. A wide set of strategies have evolved over time to provide guidelines for the decision makers but many of these strategies share a common foundation in process management that is based on decoupling points and decoupling zones. The strategies concerned here are segmentation, leagility, customization, postponement, servitization, sustainability, outsourcing, and visibility.
\end{abstract}

Keywords: Decoupling points, segmentation, leagility, customization, postponement, servitization, closed-loop, outsourcing, visibility.

\section{$1 \quad$ Introduction}

Several concepts related to strategies for production and supply management, hereafter referred to as supply chain management strategies, have been developed over the years covering a wide range of scenarios. As the market requirements change the concerned businesses have to evolve to stay competitive. Through this process the concept of supply chain management (SCM) has become fragmented and created a need for a more knowledge on fundamental properties that are shared between different concepts and strategies. A monolithic approach to SCM covers a wide range of issues that are complex and challenging to handle simultaneously. The decisions involved can be categorized from a transformation perspective into three layers as suggested by Wikner [1]. At the company layer a legal perspective is dominant since this involves the issue about who is actually the sponsor of the transformation. This is the layer where the financial transactions are in focus. The financial transactions are however a consequence of activities being performed at a physical layer where the type of transformation, such as manufacturing, transportation or distribution are handled by SCM. The physical layer does, however, rest on a generic process foundation represented by a logical layer based on generic transformations. This generic layer is the foundation for process management and consist of four decision categories [1] that can be used at the logical layer and this is the foundation below. First a short summary of the logical layer is provided based on process management. Thereafter eight SCM strategies are outlined and finally the SCM strategies are interpreted in terms of the generic decoupling framework. 


\section{Process Management Decoupling Framework}

Process management as used here refers to a generic approach to managing flow based on some fundamental and generic decision categories. Four flow based decision categories are used below based on [1]:

1. Flow driving involving the separation of speculation from commitment to customer order through the customer order decoupling point (CODP) and the customer order decoupling zone (CODZ).

2. Flow differentiation related to the uniqueness of the product ranging from standard, market unique, product to customer order unique special product which are separated by the customer adaptation decoupling point (CADP) and the customer adaptation decoupling zone (CADZ).

3. Flow delimitation concerns the reach of controllability. The flow can be separated into logical entities and the separation interface is related to the purchase order decoupling point (PODP) and the purchase order decoupling zone (PODZ).

4. Flow transparency is the fourth category and covers the availability of information where the demand information decoupling point (DIDP) limits the extension of demand information and the supply information decoupling point (SIDP) limits the extension of supply information.

These four categories are illustrated in Fig. 1 in combination with the strategic lead times that are critical for positioning these decoupling points and decoupling zones.

\section{Supply Chain Management Strategies}

The physical perspective is related to the physical transformation performed in the supply chain. The intention here is not to give a comprehensive and all-encompassing view of a set of SCM strategies but rather to outline some insights on key properties in preparation for the discussion about how they can be interpreted in terms of the generic process management layer.

\section{Segmentation}

Segmentation is related to that the supply chain should be designed to fulfil specific customer requirements [2], which may require that separate supply chains are designed for different markets. This has been an important part of supply chain design since the early days of materials management and this field of research has evolved over time to segmented supply chain design [3]

\section{Leagility}

Whereas segmentation mainly targets the customer service aspect of SCM a separate stream of research has put more emphasize on the properties of supply. Leagility is focusing on the fundamental issue of how to combine lean, with emphasis on heijunka and levelled flow with agile, with emphasis on flexibility and speed. The combination has been referred to as "leagility" $[4,5]$. Leagility in this context basically represents how to balance efficiency with responsiveness. 


\section{Customization}

Leagility is a concept that decouples the supply chain but does not include any explicit consideration of customization, i.e. to which extent the product is made unique for a specific customer. Lampel and Mintzberg [6] provided a comprehensive framework for categorization of customization. Note that this strategy encompasses a wide range of customization related strategies ranging from mass-customization [7] to engineer-to-order [8].

\section{Postponement}

In parallel to segmentation, leagility, and customization a separate stream of research has progressed and is referred to as postponement where decisions are postponed to as late as possible for better decision support. In the literature, postponement dates back to the 1950's when the concept was introduced [9]. The concept of postponement was then developed further [10] in terms of time, form, and place. Pagh and Cooper [11] outlined a framework emphasizing speculation and postponement in terms of manufacturing as well as distribution to identify a set of strategies.

\section{Servitization}

The four strategies outlined above all originates in the context of physical goods. Goods only has turned out to be a difficult strategy for many companies with limited access to low-cost manufacturing. An alternative strategy is to deliver a package of goods and services to the customers [12]. This approach has also been termed servitization [13] and is a subset of the more general concept of services.

\section{Sustainability}

By including services in the SCM strategy it is possible to take a more comprehensive approach to supply chains and to involve the whole life cycle of a product. SCM strategies are generally based on the forward supply chain but also a closed-loop perspective has emerged involving reverse flows. This topic originates in recycling which has evolved into product recovery management and the integrated supply chain [14]. This is also referred to as the closed-loop supply chain [15] which encompasses both forward flows and reverse flows and in addition is closely related to the topic of sustainability [16].

\section{Outsourcing}

Considering the resources performing the processes in the supply chain it is relevant to make a strategic choice related to the ownership of the resources. Originally the logical choice was to obtain vertical integration [17] to obtain control but in many cases this is not possible, nor desirable. Instead the emphasis on core competence [18] grew stronger and as a consequence the intent was to outsource activities not considered as based on the core competence of the business [19]. This approach creates a better focus in each individual business but also contributes to the overall complexity of the supply chain as more actors are involved in the supply network.

\section{Visibility}

Competitive SCM requires access to information about the actual state of the supply chain. The information basically concerns information about demand that creates requirement for resources and information about supply and the available resources. 
In the SCM context the main focus has been on demand information where demand visibility has turned out as an important factor for e.g. mitigation of the bull-whip effect [20]. Visibility for resource capacity, i.e. supply, has evolved over time from simple sharing of information to a strategic element [21] where visibility across several dimensions can be important [22].

\section{Supply Chain Management Strategies Interpreted in Terms of the Process Management Decoupling Framework}

The eight SCM strategies outlined above have been associated with decoupling related aspects by different researchers and below follows a summary of this work. Fig. 1 illustrates the connection between the physical perspective represented by the SCM strategies and the logical perspective represented by the decoupling framework based on [1]. Each strategy is expressed in terms of "level of" since the decoupling framework is based on positioning of decoupling points and decoupling zones across a leadtime based scale.

\section{Level of segmentation}

The explicit connection to market segments was emphasized by Hoekstra and Romme [23 p. 65] when they introduced the concept of "product-market combination". They also introduced the concept of decoupling points for designing integral logistics structures and consequently they early realized the critical link between segmentation and decoupling points. Thereafter segmentation using decoupling points have emerged as a separate path of research, see e.g. [24]. In particular the aspect of flow driver (related to CODP and CODZ) is emphasized but implicitly this is also closely connected to how to create offerings that are adapted to specific market requirements and hence there is also a strong dependence on flow differentiation (related to CADP and CADZ).

\section{Level of leagility}

Leagility was coined by Naylor, Naim [5] and was basically defined using the CODP as a point of reference. Over time this idea has been further developed but still it is mainly the flow driver that is used as a point of reference (related to CODP and CODZ). The CODP has been emphasized by different authors in both lean and agile.

\section{Level of customization}

Customization involves making a product unique for a particular market or even an individual customer. The topic of customization is broad but in particular two distinct approaches can be identified. First, it has been suggested that the flow driver should be considered from both a production perspective and an engineering perspective [25], which has also been interpreted from a mass customization perspective [26]. Second, the issue of customization and uniqueness provides additional complexity when the perspectives of customer and supplier are treated separately [27]. Hence customization is mainly concerned with flow differentiation (related to CADP and CADZ). 


\section{Level of postponement}

Postponement is a successful model for reduced risk exposure in both production and distribution. Central distribution and postponed product differentiation enables critical decisions to be postponed and to a larger extent become customer order driven. This provides an obvious connection to the flow driver (related to CODP and CODZ) as pointed out by e.g. [28]. Postponement is however also related to flow differentiation (related to CADP and CADZ) which is explicitly stated in [29] as point of product differentiation and by [30] as differentiation point.

\section{Level of servitization}

The level of servitization was, until relatively recently, not interpreted in terms of decoupling points. This is however appropriate when considering that there are many similarities between customer-order-driven activities and services. This analogy was first noted by Fließ and Kleinaltenkamp [31] and later further developed by [32] and [33]. In both these cases the emphasis were on flow drivers (related to CODP and CODZ) but obviously a fundamental aspect of services is the uniqueness of the offering and that it is differentiated for the customer (related to CADP and CADZ).

\section{Level sustainability}

Recycling, reverse flows, product returns, and closed loop supply chains are all terminology related to sustainable supply chains. To a large extent the theory development for this field has been separate from theory for forward flow supply chains. Reverse flows are usually more prone to stochastic events and consequently of much more uncertain character. Blackburn, Guide [34] did however highlight that many concepts used in forward flow supply chains have a great potential also for reverse flows. One area they mentioned was postponement and [35] developed this line of thinking in terms of decoupling points and in particular the flow driver was considered (related to CODP and CODZ).

\section{Level of outsourcing}

The first inclusion of purchased material into a decoupling point framework was by Hoekstra and Romme [23] when they identified Purchase and make to order (PMTO) as a separate product-market combination. In this sense they considered purchasing as something taking place before production activities and hence included this in flow driving (related to CODP and CODZ). An alternative was developed by [36] that used two-dimensional CODP with production and engineering dimension and extended this approach to also include purchasing as a separate dimension making it into a three dimensional flow driver. An additional approach was suggested by [37] that instead focused on if resources are within or outside the scope of control. In this sense they combined the flow driver with flow delimitation (related to PODP and PODZ) to more explicitly capture the controllability of the flow. In this context different scenarios of customer-supplier interaction can be defined by combining flow driving and flow delimitation.

\section{Level of visibility in demand and supply}

Visibility is a supply chain strategy with a slightly different approach compared to the above. Instead of focusing on the decision maker and how to use information when 
making a decisions, visibility is focused on the availability of information for the decision maker. For demand visibility Mason-Jones and Towill [38] introduced the concept of information decoupling point. Since different types of information are involved in visibility this is here referred to as demand information decoupling point (DIDP). Supply visibility has not received the corresponding interest from a decoupling perspective since availability of this kind of information is usually assumed. A corresponding decoupling point for supply information was suggested by [1] and is referred to as supply information decoupling point (SIDP).

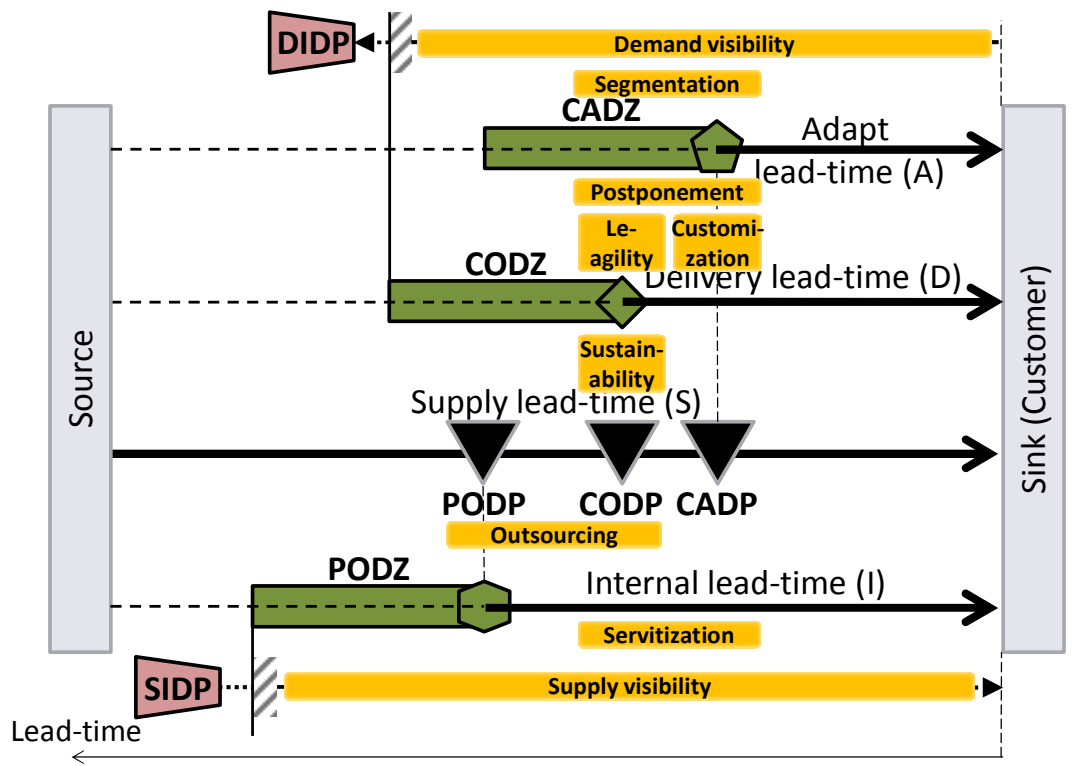

Fig. 1. SCM strategies and the decoupling framework

This short overview of how the eight SCM strategies can be interpreted in terms of decoupling points and decoupling zones has highlighted some key similarities between the SCM strategies and also illustrated that the decoupling framework represent some fundamental aspects of SCM. It is, however, important to note that even if the analogy identifies some fundamental similarities between the different SCM strategies there are still many other aspects of the SCM strategies that are not covered here.

Acknowledgement. This research has been performed in collaboration with six companies in the projects KOPeration and KOPtimera. The projects are funded by the Swedish Knowledge foundation (KKS), Jönköping University and the participating companies.

\section{References}

1. Wikner, J.: On decoupling points and decoupling zones. Production \& Manufacturing Research, 167-215 (2014) 
2. Sharma, A., Lambert, D.M.: Segmentation of markets based on customer service. International Journal of Physical Distribution \& Logistics Management 20(7), 19-27 (1990)

3. van der Veeken, D.J.M., Rutten, W.G.M.M.: Logistics service management: Opportunities for differentiation. International Journal of Logistics Management 9(2), 91-98 (1998)

4. Mason-Jones, R., Naylor, B., Towill, D.R.: Engineering the leagile supply chain. International Journal of Agile Management Systems 2(1), 54-61 (2000)

5. Naylor, B., Naim, J.M.M., Berry, D.: Leagility: Integrating the lean and agile manufacturing paradigms in the total supply chain. International Journal of Production Economics 62(1-2), 107-118 (1999)

6. Lampel, J., Mintzberg, H.: Customizing Customization. Sloan Management Review 38(1), 21-30 (1996)

7. Davis, S.M.: Future perfect (1987)

8. Hicks, C., McGovern, T., Earl, C.F.: Supply chain management: A strategic issue in engineer to order manufacturing. International Journal of Production Economics 65(2), 179190 (2000)

9. Alderson, W.: Marketing Efficiency and the Principle of Postponement. Cost and Profit Outlook 4 (September 1950)

10. Bucklin, L.P.: Postponement, speculation and the structure of distribution channels. Journal of Marketing Research 2(1), 26-31 (1965)

11. Pagh, J.D., Cooper, M.C.: Supply chain postponement and speculation strategies: How to choose the right strategy. Journal of Business Logistics 19(2), 13-33 (1998)

12. Wise, R., Baumgartner, P.: Go Downstream: The New Profit Imperative in Manufacturing. Harvard Business Review 77(5), 133-141 (1999)

13. Vandermerwe, S., Rada, J.: Servitization of business: Adding value by adding services. European Management Journal 6(4), 314-324 (1988)

14. Thierry, M., et al.: Strategic issues in product recovery management. California Management Review 37(2) (1995)

15. Daniel, V., Guide Jr., R., Wassenhove, L.: Closed-loop Supply Chains. In: Klose, A., Speranza, M.G., Wassenhove, L. (eds.) Quantitative Approaches to Distribution Logistics and Supply Chain Management, pp. 47-60. Springer, Heidelberg (2002)

16. Linton, J.D., Klassen, R., Jayaraman, V.: Sustainable supply chains: An introduction. Journal of Operations Management 25(6), 1075-1082 (2007)

17. Ford, H., Crowther, S.: Today and tomorrow, 281 p. Doubleday, Page \& Company, Garden City, NY (1926)

18. Prahalad, C.K., Hamel, G.: The core competence of the corporation. Harvard Business Review 68(3), 79-91 (1990)

19. Bettis, R.A., Bradley, S.P., Hamel, G.: Outsourcing and Industrial Decline. The Executive 6(1), 7 (1992)

20. Forrester, J.W.: Industrial dynamics: a major breakthrough for decision makers. Harvard Business Review 36(4), 37-66 (1958)

21. Lamming, R.C., Caldwell, N.D., Harrison, D.A., Phillips, W.: Transparency in supply relationships: Concept and practice. Journal of Supply Chain Management 37(4), 4-10 (2001)

22. Hultman, J., Axelsson, B.: Towards a typology of transparency for marketing management research. Industrial Marketing Management 36(5), 627-635 (2007)

23. Hoekstra, S., Romme, J. (eds.): Integral logistic structures: developing customer-oriented goods flow, xii, 164 p. Industrial Press, New York (1992)

24. Hilletofth, P.: How to develop a differentiated supply chain strategy. Industrial Management \& Data Systems 109(1), 16-33 (2009) 
25. Wikner, J., Rudberg, M.: Integrating production and engineering perspectives on the customer order decoupling point. International Journal of Operations \& Production Management 25(7/8), 623-641 (2005)

26. Rudberg, M., Wikner, J.: Mass customization in terms of the customer order decoupling point. Production Planning \& Control 15(4), 445-458 (2004)

27. Wikner, J., Bäckstrand, J.: Decoupling points and product uniqueness impact on supplier relations. In: 4th World Conference P\&OM, Amsterdam (2012)

28. Towill, D.R.: Decoupling for supply chain competitiveness (material flow decoupling). Manufacturing Engineer 84(1), 36-39 (2005)

29. García-Dastugue, S.J., Lambert, D.M.: Interorganizational time-based postponement in the supply chain. Journal of Business Logistics 28(1), 57-81 (2007)

30. Wikner, J., Wong, H.: Postponement based on the positioning of the differentiation and decoupling points. In: Olhager, J., Persson, F. (eds.) APMS 2007. IFIP AICT, vol. 246, pp. 143-150. Springer, Heidelberg (2007)

31. Fließ, S., Kleinaltenkamp, M.: Blueprinting the service company: Managing service processes efficiently. Journal of Business Research 57(4), 392-404 (2004)

32. Moeller, S.: Customer Integration-A Key to an Implementation Perspective of Service Provision. Journal of Service Research 11(2), 197-210 (2008)

33. Wikner, J.: A service decoupling point framework for logistics, manufacturing, and service operations. International Journal of Services Sciences 4(3), 330-357 (2012)

34. Blackburn, J.D., Daniel, V., Guide Jr., R., Souza, G.C., Van Wassenhove, L.N.: Reverse supply chains for commercial returns. California Management Review 46(2), 6-22 (2004)

35. Wikner, J., Tang, O.: A structural framework for closed-loop supply chains. The International Journal of Logistics Management 19(3), 344-366 (2008)

36. Mello, M.H., Semini, M., Haartveit, D.E.: A framework to integrate engineering, procurement, and production on the customer order decoupling point. In: Proceedings of the 17th International Working Seminar on Production Economics, Innsbruck, Austria, February 20-24 (2012)

37. Wikner, J., Bäckstrand, J.: Aligning operations strategy and purchasing strategy. In: EurOMA Conference, Cambridge, UK (2011)

38. Mason-Jones, R., Towill, D.R.: Using the information decoupling point to improve supply chain performance. International Journal of Logistics Management 10(2), 13-26 (1999) 